\title{
Digital organisational readiness: experiences from \\ manufacturing companies
}

\author{
Carla Gonçalves Machado
}

Technology Management and Economics, Chalmers University of Technology, Gothenburg, Sweden and

Jönköping International Business School, Jönköping University, Jonköping, Sweden

Mats Winroth and Peter Almström

Technology Management and Economics, Chalmers University of Technology, Gothenburg, Sweden

Anna Ericson Öberg

Operations Quality and Safety, Volvo Construction Equipment, Arvika, Sweden

Martin Kurdve

Technology Management and Economics, Chalmers University of Technology, Gothenburg, Sweden and

Materials and Production, RISE Research Institutes of Sweden AB,

Mölndal, Sweden, and

Sultan AlMashalah

Technology Management and Economics, Chalmers University of Technology, Gothenburg, Sweden

\begin{abstract}
Purpose - This research aims to identify and organise the conditions of organisational readiness for digital transformation.

Design/methodology/approach - This qualitative study comprises three case studies within manufacturing companies from different sizes and industries located in Sweden. Plant visits and in-depth interviews bring to light companies' experiences with initial steps towards digital transformation. A set of conditions for digital organisational readiness was translated into a questionnaire and tested with one of the studied companies.

Findings - This paper organises and tests digital organisational readiness conditions to support companies' initial steps on digital transformation. The results are put in perspective of established change management theory and previous studies about digital transformation. The findings will conclude in a questionnaire to support dialogue and digital organisational readiness assessments.
\end{abstract}

(C) Carla Gonçalves Machado, Mats Winroth, Peter Almström, Anna Ericson Öberg, Martin Kurdve and Sultan AlMashalah. Published by Emerald Publishing Limited. This article is published under the Creative Commons Attribution (CC BY 4.0) licence. Anyone may reproduce, distribute, translate and create derivative works of this article (for both commercial and non-commercial purposes), subject to full attribution to the original publication and authors. The full terms of this licence may be seen at http:// creativecommons.org/licences/by/4.0/legalcode

The SMART PM project is granted by the Swedish Strategic Innovation Program Production 2030, financed by Vinnova (2018-01583). The support is gratefully acknowledged by the authors. Special thanks are given to the representatives from the companies for their time and resources they have assigned in support of the research. This research is also supported by the Chalmers Production Area of Advance (AoA Production).
Digital organisational readiness

Received 17 May 2019

Revised 3 May 2020

14 September 2020 18 March 2021

Accepted 30 March 2021 
JMTM 32,9

168
Research limitations/implications - Additional conditions for the initial phase of digital transformation could possibly be found if more cases had been included in the study.

Practical implications - The article identifies a set of conditions translated into a questionnaire that should be used as a dialogue tool to create strategic alignment and support companies in their initial discussions. If this process can be faster and more efficient, the company can achieve a competitive advantage against competitors.

Originality/value - This research's relevance relies on the fact that companies are advancing in adopting digital technologies without being ready from an organisational perspective. This gap creates barriers for companies' digital maturing processes, stopping them from having full access to digital technologies' benefits.

Keywords Manufacturing industry, Organisational change, Industry 4.0

Paper type Research paper

\section{Introduction}

The Fourth Industrial Revolution, or Industry 4.0, promises to increase productivity, reduce energy and material consumption and improve working conditions in manufacturing. Industry 4.0 represents the integration of the cyber-physical-systems (CPS) into the manufacturing operations, supported by digital technologies. People, machines and resources are linked through vertical integration, while actors in the value chains are linked horizontally in a digital ecosystem created by CPS (Lichtblau et al., 2015; Kane et al., 2018).

Digital transformation represents the strategic transformation of all aspects of the business, creating a new ecosystem where technology creates and delivers value to the stakeholders, enabling the company to adapt more quickly to changing circumstances (Unruh and Kiron, 2017; Newman, 2017; Ross, 2019). McLaughlin (2017) and Kane et al. (2018) pointed out that the digital transformation is not technology-centric but represents an organisational change process. The whole firm is developing new ways to use technology to build innovation in products, services and business processes.

However, many companies still understand digital transformation only as "advance digitisation" and not as a continuous process of changes, adaptation and improvements (Unruh and Kiron, 2017; Ross, 2019). Companies in the manufacturing industry are seeking guidance on how to prepare and organise themselves to implement the principles of Industry 4.0 and they are not ready for the changes and opportunities related to the digital transformation. Besides numerous publications, there are still gaps to clarify the impacts of Industry 4.0 on companies and how companies can navigate through the digital transformation journey (Schuh et al., 2017; Hermann et al., 2019).

Garengo et al. (2005) identified that small companies tend to put more efforts into technical and technological capabilities rather than analysing and developing supporting managerial practices. Machado et al. (2019b) identified that challenges or barriers for digital transformation faced by manufacturers could be avoided or minimised, with a more structured initiation phase focussing on the organisational and managerial practices. Jumping into technological aspects can make managers and engineers forget or only discuss superficially what the purpose of the digital transformation is. How it connects to the company's goals or competitive advantages that can be reached by increasing digitalisation might be overlooked.

This research aim is to identify and organise the conditions of organisational readiness for digital transformation. Two research questions will be guiding the study:

$R Q 1$. What organisational conditions need to be assessed to evaluate the organisational readiness for digital transformation in manufacturing companies?

$R Q 2$. How should these organisational conditions be organised to support the startingup processes of digital transformation? 
To answer these questions, a series of qualitative analyses were conducted, further explained in the following sections. The "Result" section includes the outcomes of studies carried out in partnership with three manufacturing companies and a compilation of digital organisational readiness conditions and further recommendations.

\section{Background}

A survey conducted by Mckinsey (2016) concluded that it is critical building appropriate foundations for digital transformation, i.e. establishing cross-functional governance, attracting digital talent, enabling collaboration in the ecosystem, managing data as a business asset, ensuring cybersecurity end-to-end and implementing information technology (IT) systems architecture. However, this can be turned into a big challenge since multidisciplinary activities demand experts from different domains, which may not be found in the companies, especially in the small- and medium-sized companies (SMEs) (Colli et al., 2018).

To overcome internal resistance against the digital transformation, Yeow et al. (2018) and Issa et al. (2018) provide recommendations: communicate a clear strategy; establish a dedicated and cross-departmental team to increase workforce competence and manage external resources; describe a blueprint with all information flows, processes and tools within the company; define a set of measurable indicators; focus on business and digital strategies integration supported by a digital department to align digital capabilities provided by the technologies with the business goals.

Kane et al. (2018) identified that digitally mature companies present similar characteristics. These companies have established: decentralised decision-making systems; the digital transformation at the core of the organisation with a clear purpose; a clear and well-communicated digital strategy; continued development of skills, talents and capabilities to implement the strategy; a solid and digital fluent leadership; a higher level of flexibility and ability to adapt quickly; and key performance indicators (KPIs) to align people and processes. Bosman et al. (2020) and Machado et al. (2018) advise that to accelerate Industry 4.0, manufacturers need to apply strategic analysis consistently and continuously. The conciliation of the top-down and bottom-up approach is necessary to identify the impact of the changes in the performance dimensions and into the company's decision areas.

Hermann et al. (2019) developed four steps for Industry 4.0 process transformation: a review of current processes, design of Industry 4.0 goals, developing a strategic implementation plan and implementing the planned strategies. The authors suggest using workshops, maturity models for assessments, development of strategic plans for improvement and processes optimisation and organisation of activities following principles and measures derived from project management models. However, results published by Pessot et al. (2020, p. 18), summarised in Table 1, indicate that manufacturing companies still need to develop adequate organisational structures and managerial capabilities to enable digital transformation.

Nosalska et al. (2019) recommended that engineers and managers work together, developing a shared vision and understanding of Industry 4.0 to facilitate the crossfunctional dialogue. For SMEs, it is critical to ensure top management's commitment and define the vision, goals and investments at the strategic level, involving middle managers and operators/workers in the process. The authors stated that a company could only claim Industry 4.0 implementation when the technology supports the fundamental business changes.

Nadler et al. (1995) identified as primary drivers for organisational change: processes of discontinuity in the organisational structure; technological innovation; macroeconomic crises and trends; legal changes and regulations; market and competitive forces; and organisational growth. All these drivers can be applied in the context of digital transformation (Kane et al., 2018). Thus, it 


\section{JMTM 32,9}

170
Dimension

Strategy

Strategy

70

Organisation

(O)

education and a high average age of
employees and managers; leveragin digital technologies for internal

Management Adopt digital solutions for enriching

Technology Organisation for implementing and

Table 1.

Challenges for digital transformation in manufacturing companies communication; evaluate disruption of technologies on how people work customer service; focus on sustainability and energy efficiency in operations management embedding data analysis across company business processes and functions; lack of information about potentialities of newer

Lack of clear vision/strategy; need to perform gradual and incremental changes; define the proper amount of investments aligned with and certification; underestimate risks related to cybersecurity; assess disruption in business models

Lack of talented/skilled people and leadership from top management; low level of digital technologies; low level of importance and utilisation and solutions for humanmachine interaction
Source(s): Adapted from Pessot et al. (2020, p. 18)
Drivers for overcoming challenges

Develop a well-defined and overall strategy for digital transformation with clear goals and benefits; identify critical roles; assign clear responsibilities; consider social and environmental objectives for the change beyond technological and business ones

Collaborative organisational structure; develop and improve soft and basic hard (digital) skills; investment in training programs integrating different means and methods (e.g. external courses and experience-based learning)

Data flow integration with both upstream and downstream supply chain actors; introducing new third-party partners to expand the knowledge base and enhance connectivity according to the transformation goals; increasing digitalisation of product portfolio; persist in using renewable energy sources

Have a clear picture of the appropriateness of overall IT infrastructures and digital technologies maturity level; take the digital technologies' advantages to improve flexibility (workforce, operations and response to market demands)

is possible to infer that the digital transformation needs to be supported by a robust organisational changing process.

In the literature, there are different models for managing organisational changes, e.g. Peters and Waterman (1982), Kotter (1996, 2014), Mintzberg (2003) and Galbraith (2005). In general, these models consider that the organisational aspects should be balanced, interrelated and interdependent. According to Appelbaum et al. (2012), Kotter's model (1996) is well-recognised to support organisational changes, despite criticisms regarding its validation from a more practical application than scientific approach.

Kotter's models $(1996,2014)$ are based on processes for implementing and accelerating the changes, covering a series of processes that can be summarised as the development of a sense of urgency, the establishment of a change process guiding team, creation and communication of the vision to promote stakeholders engagement, creation of empowerment conditions (structure and governance policies), generate short term-wins, consolidate and promote achieved gains, developing and promoting a new culture. The implementation involves innovation, learning and knowledge generation and may not be implemented in sequence, but more as a sum of concurrent change processes involving different stakeholders. The teams need to work through overlapping change processes over time (Pollack and Pollack, 2015).

Weiner (2009, pp. 2-3) define organisational readiness for change as " $a$ multi-level construct", with different levels of analysis and implementation moving through individuals, groups, units, departments, or linked in a network of individuals and work units. Enablers of 
action and change are shared values, beliefs, group capabilities and a receptive environment for innovation and change among the networks. The structural/psychological approach infers that organisations with similar resources and organisational structures can present different results when implementing changes resulting from how they plan, aggregate and utilise the resources and processes available. The author advises that organisational readiness does not guarantee the success of a complex organisational change, especially if it is poorly designed and lacks consistent and accurate information originated from direct experience (Weiner, 2009).

Some questions can help identify the level of commitment and engagement for change, e.g. does the organisation value the change? Does the organisation believe that it is necessary or essential? Is it clear what is required to implement the change? Are enough resources available for implementing the change? Can the change steps be implemented effectively given the current scenario? How the actions/activities should be sequenced? Are the organisational culture and policies appropriate for innovation and change processes?

Weiner (2009, p. 5) also advises that if the majority of the "(. . ) organisational members agree in their readiness perceptions, then analysis of organisational readiness as a shared team property can proceed". The author alerts that creating a sense of urgency for the change is valuable for situations when the level of complacency is high but is not indicated when the level of uncertainty is high. End-user involvement is recommended and valued for tailoring strategies and changing processes based on local needs, constraints and opportunities.

The Project Management Institute (PMI) argue that believing that leadership/ sponsorship, vision, communication and resources can overcome the challenges and barrier for the change can be a "faulty assumption" (Combe, 2014). To PMI, change readiness is based on three drivers: cultural alignment between the existing norms and the proposed changes; commitment of the leadership (all levels) to promote and sustain the change as part of the overall strategic agenda; capacity readiness to provide support the work processes, knowledge, experience, skills and all the resources required to implement and sustain the change.

According to the PMI, to build confidence and reduce barriers for change, some parts are necessary: promote a higher level of involvement and decision-making participation, crossboundary teaming and problem-solving, pilots and simulations, user proof-of-concept tests and limited rollouts, freeing time of people needed to manage the change, readiness measured in degrees towards the desired target, considering different viewpoints and promoting continuous assessment and decisions/actions. The PMI uses a set of questions for assessment of capacity, commitment and culture that can be adapted to the needs of the project or program, implemented via interviews and workshops for assessment activities (Combe, 2014).

Roos and Nilsson (2020) defend that the organisational readiness for change depends on the content (what needs to be changed), the processes (phases or steps), the context (the environment) and the attributes (people). The authors found that "motivation" for change is positively related with beliefs; "psychological safety" to how skills and competencies have been valued and applied; "cohesion" with a focused team; "knowledge creation" with innovation; "engagement" with clear roadmaps and goals; and finally, "readiness for change" is supported by a strong motivation for implementing the change processes. The authors discussed the relevance of workshops to promote, clarify and prepare the change groups. During such workshops, practitioners need to make sure that the participants are joining because they value the change, that skills and competencies will be used, the level of agreement is verified, the group has a clear vision of the change, and a good level of knowledge is kept all the time. Most of all, it is necessary to ensure that people are motivated, the change's psychological safety is promoted, and group cohesion is encouraged. 
JMTM 32,9

\subsection{Organisational readiness for digital transformation}

The transformation process can take many years and require digital competencies, capabilities and changes across the organisation (Singapore Economic Development Board, 2017; Schuh et al., 2017; Kane et al., 2018). Previous studies identified organisational and managerial conditions for supporting digital transformation.

Geissbauer et al. (2016) stated that the path of organisational readiness starts by evaluating a company's digital situation and current capabilities to enhance future goals and strategy, developing skills and culture, and building a new ecosystem through integrating the value chains. Digital transformation should start with a deep analysis of each company's situation and goals, and the necessary changes, including changes in the business models.

De Sousa Jabbour et al. (2018) listed a set of success factors for digital transformation: management leadership with a transformational style to inspire followers; readiness for organisational change and change management capabilities; top management commitment foreseeing organisational opportunities for integrating Industry 4.0 technologies; strategic alignment between technology and organisational goals; training providing the necessary knowledge and skills for employees and supply chain partners; empowerment to support the level of autonomy and responsibility demanded by the decentralised decision-systems; teamwork (a specific group of key employees) whose values, attitudes, moods and emotions reflect all employees; communication of strategies and objectives promoting collaborative workplace; organisational culture to support technology adoption and reduce resistance to change; project management approach for pilots and changing processes; and considering national culture and regional differences that can either facilitate or create difficulties in adopting new technologies.

Ghobakloo (2018) provided a roadmap for organisational readiness starting with a definition of the digital strategy in the short, medium and long-term, committed leadership, resource allocation (transition team), integration of the systems and infrastructure and project plans. The author stated that not all companies have adequate IT readiness or are large enough to handle horizontal integration without losing competitiveness, so different types of partnerships or even acquisitions and mergers need to be planned. Complementing, assessment of available skills, strategic recruitments and training programs need to be in place, as well as conditions for cross-functional integration (Pirola et al., 2019).

Lokuge et al. (2019, p. 446) define digital organisational readiness "as an organisation's assessment of its state of being prepared for effective production or adoption, assimilation and exploitation of digital technologies for innovation." The model tested by the authors to assess organisational readiness for digital innovation is formed by seven subconstructs: resource readiness (flexibility to configure and reconfigure resources), cultural readiness (core values, decentralised decision-making system, risk aversion), strategic readiness (communication, vision and goals, strategy), IT readiness (portfolio, support and infrastructure), innovation valence (the value the stakeholders attribute to the change - motivation, empowerment, attitude), cognitive readiness (knowledge base, skills, level of adaptability of the staff) and partnership readiness (external stakeholders supporting the digital transformation). Resource, cultural and IT readiness were identified as the main contributors to organisational readiness.

Machado et al. (2019a) analysed twenty-one different digital readiness assessment models (listed in Appendix 1). The models' frequent dimensions are organisation and governance; digital strategy and business models; connectivity and IT systems architecture; data collection and analytics; machine and systems integration; and skills and competences. Not all models analysed by Machado et al. (2019a) clearly describe initial steps for digital transformation; however, the guidelines provided by thirteen models were summarised in five main steps: (1) digital readiness assessment, identifying opportunities and threats; 
(2) setting vision, goals and strategies; (3) piloting projects; (4) developing improvement roadmaps; (5) and, measuring the value and effectiveness of the initiatives.

Hizam-Hanafiah et al. (2020) analysed thirty Industry 4.0 readiness models. According to the review, the most common dimensions to be evaluated for digital readiness are technology, people, strategy, leadership, process and innovation.

Therefore, based on the literature review presented, a set of conditions was organised to evaluate the starting-up process for organisational readiness for digital transformation:

(1) Identify the needs and strategic benefits of digital transformation (Weiner, 2009; Machado et al., 2019b; Roos and Nilsson, 2020).

(2) Identify opportunities and risks of digital transformation (Weiner, 2009; Hermann et al., 2019; Machado et al., 2019a, b).

(3) Define digital capabilities, competencies and resources for digital transformation (Combe, 2014; Kane et al., 2018; De Sousa Jabbour et al., 2018; Pessot et al., 2020).

(4) Promote digital leadership and cross-functional/units' engagement (Kane et al., 2018; Colli et al., 2018; Nosalska et al., 2019).

(5) Define the vision, goals and strategy for digital transformation (Kotter, 2014; De Sousa Jabbour et al., 2018; Nosalska et al., 2019; Pessot et al., 2020).

(6) Promote and enable clear communication with all stakeholders (Kotter, 2014; Weiner, 2009, Geissbauer et al., 2016; Kane et al., 2018; Machado et al., 2019a,b).

(7) Measure digital transformation progress (KPIs) (Weiner, 2009, Combe, 2014; Yeow et al., 2018; Issa et al., 2018; Machado et al., 2019a, b; Bosman et al., 2020).

(8) Establish mechanisms for digital knowledge management (De Sousa Jabbour et al., 2018; Pessot et al., 2020).

(9) Stakeholders' empowerment (Kotter, 2014; De Sousa Jabbour et al., 2018; Pessot et al., 2020).

(10) Escalate the digital transformation across the value-chain (Ghobakloo, 2018; Colli et al., 2018; Pirola et al., 2019).

As a conclusion of this review, the organisational readiness for digital transformation has its foundation: cross-functional governance, digital and top management leadership, dedicated teams leading the change process, defining the purpose and goals and putting digital transformation as the strategic core. It is necessary to have a strong focus on competence and skills development, to review traditional organisational structures, use a robust and continuously changing process model, have business and digital strategy alignment, use continuous assessment to support investment decisions and define an appropriated performance management system. These points have adherence with the findings presented by De Sousa Jabbour et al. (2018).

\section{Research design}

The research design comprises two parts, the first dedicated to collect and analyse manufacturing companies' digital transformation experiences. The second to identify a set of organisational conditions that need to be assessed and improved in the start-up phase to build the foundation of digital transformation. Weiner (2009) advice that testing an organisational theory requires a multi-organisation design in which a set of organisations implements a common, or at least comparable, complex organisational change. However, testing 
JMTM 32,9

hypotheses at an intra-organisational level of analysis can be feasible if the units involved have some autonomy in the changing processes.

Yin (2014) indicates case studies when the goal is to analyse contemporary events. According to Stuart et al. (2002, p. 420), cased-based research “(. . .) is a scientific approach that attempts to ground theoretical concepts with reality". Therefore, a case-based approach was conducted with a series of interviews and plant visits to collect data and insights for developing a set of conditions for digital organisational readiness. Three companies were analysed, and their relevance relies on the fact that they have already faced the challenges of the initial phases of digital transformation and could provide a critical retrospective of the starting-up processes. A short description of the companies is provided below:

(1) Small company 1 (SC1): an SME manufacturer founded in 1961 specialised in plastic packaging solutions. The case unit is dedicated to producing plastic bottles and plastic cans for chemical engineering products, pharmaceuticals and food. The company has the ISO 9001 and ISO 14001 certifications. Five interviews were conducted with two plant managers, the automation and maintenance manager and two production engineers.

(2) Larger company 2 (LC2): a heavy industry company operating since 1883. The company serves different industries in three main divisions: energy, food and water, marine. The manufacturing unit analysed is certified by ISO 9001. Interviews were conducted with the person responsible for the technology development program and the program manager for smart manufacturing.

(3) Larger company 3 (LC3): a company specialising in heavy equipment for construction and related industries. Operating since 1966, the company has the ISO 9001, ISO 14001 and OHSAS 18001 certifications. In total, six interviews were conducted with the group responsible for the digitalisation project: management systems and data analysis director, manufacturing manager, maintenance manager, project manager, IT manager and electronic engineer.

Plant visits were used to observe companies' processes, evaluate the current use of digital technologies and gather data about technological infrastructure. Stuart et al. (2002) highlights the risk of bias due to the observer's prior experiences and background; in this sense, the researchers present different and complementary backgrounds and expertise within manufacturing companies and digitalisation. The plant visits' scope was previously discussed with the companies prioritising some specific areas and processes, in general, those running digital pilot projects.

Exploratory interviews were conducted with the three companies between 2018 and 2019, guided by a questionnaire formed first by 35 questions divided into six topics: digital strategy, digital maturity models, digitalisation, investments, data analysis and KPIs (see Appendix 2). The subjects were defined based on previous studies, e.g. Kane et al. (2018) and Litchtblau et al. (2015), and the questions were developed and organised by a group formed by researchers and consultants involved in projects of digital transformation. The answers were essential to provide manufacturing companies' perspectives and experiences, challenges, readiness level, learnings and implementation processes for digital transformation.

To reduce bias and limitations of a small sample and provide a broader picture, a multiple respondent approach representing different areas was adopted, performing at least two interviews in each company within different hierarchical levels and areas, as emphasised by Stuart et al. (2002). All interviews were recorded, transcribed and reviewed by three researchers. Other sources of evidence (individual notes) were compiled in a single document 
related to each company and were validated by all the researchers. Complementary records provided by the companies were analysed to improve the company's understanding in preparation for the interviews and will not be fully reported in this document. In summary, data collection included interviews, observations and secondary/complementary documents provided by the companies. Interviews were coded/analysed using the success factors for digital organisational readiness provided by De Sousa Jabbour et al. (2018), which presents a higher level of adherence with the set of conditions summarised in section 2.

The different aspects included in the set of readiness conditions were deployed into 50 questions, tested in a study conducted at one of the units of LC3 and reported by Machado et al. (2020). After this initial study, the set of questions were reviewed, and a workshop was planned with a group of practitioners (managers, engineers and supervisors from different business units and areas) responsible for developing the LC3's global program for digital transformation. A two-day workshop, conducted in December of 2019, was facilitated by two researchers. In the first part of the workshop, the framework and the results of the previous study were presented by the researchers with the active participation of practitioners involved in the first round of tests, leading a discussion about digital organisational readiness and collecting experiences from the global team. A revised version of the questionnaire with 36 questions was presented and facilitated by the researchers and answered by the group.

Additional explanation was required for some of the questions and resulted in adjustments for clarification in the final questionnaire (Appendix 3). On the second day, the group met without the researchers' presence and divided into their specific subject areas of specialisation, reflected on the answers provided during the first day. The group also compiled feedback regarding the feasibility and validity of the questionnaire and insights on how the workshops could be replicated within their local teams, following Roos and Nilsson's (2020) recommendations about workshops' design, structure, function and applicability.

\section{Results and discussion}

\subsection{Companies' experiences}

This section summarises and discusses pertinent points to define the context of this study. The results are summarised in Table 2 , where the three cases (in columns) are described with regards to the resulting change process enabler (in rows). Many problems are not decomposable into specific domains, and the results need to be analysed without treating each issue as a "silo" but using a systemic perspective instead.

Looking at the results it is possible to identify that besides the discussions about digitalisation and digital transformation started a time ago, manufacturing companies are facing challenges. There is a lack of understanding of the principles of Industry 4.0, the transformation is discussed in ad hoc situations and, in general, production-oriented, i.e. the strategic transformation of the business model is not discussed or only in a very early stage. The results point at that the companies are part of the group that is still seeking guidance on how to prepare and organise themselves to implement the principles of Industry 4.0 and both, SME and larger companies are putting more efforts on the technical and technological side instead of the development of the Industry 4.0 foundations.

The challenges are aligned with the ones listed in Table 1, a relevant point for generalising the cases' results and analysis. When analysing the different responds, there is still not alignment regarding the reasons for increasing the level of digitalisation and the meaning/ definition of digital transformation for the companies. Therefore, the scenario is not different from the one presented in sections 1 and 2, including the lack of digital maturing characteristics listed by Kane et al. (2018), Yeow et al. (2018), Nosalska et al. (2019) and Bosman et al. (2020).

The companies agreed that the technology side is very attractive, and it is easy to forget to start at the "right" point, i.e. discussing what they would like to achieve before going into 
JMTM 32,9

\section{6}

Table 2.

Compilation of data from cases
Digital

transformation $\quad \mathrm{SC} 1-5$ interviews

20172017

Start

Vision/

definition

Connected information

systems (integration); open communication channels;

data analysis; statistical

process steering

Reasons

Improve production and maintenance processes and decision-systems

To become a digital enterprise; Data analysis and visualisation

Develop digital capabilities for real-time management; vertical integration

Strategy/value proposition

From "to stock" to "to order" model; connected business units; speed and flexibility; costs; fulfil customer needs; no digital strategy; manufacturing centric

Leadership

Top management

Sources

Business cases and workshops; internal meetings

Challenges

Lack of resources and competencies (IT/data analysis in-house; time; data quality; change management; safety; education/training; culture

Investments

Data collection (sensors); new equipment; software to control production and maintenance; cloud-based software for autonomous guided vehicles (AGV)

Data usage None

KPIs
Data + Strategy; systems standardised; strategy under development; manufacturing centric

Program managers and top management

Benchmarking; consultancy services; digital readiness assessment

Education/training; resources planning; time; IT infrastructure; data collection, storage and analysis; communication; digital knowledge and skills; organizational/ governance structure; data ownership

Technology use-cases (ad hoc initiatives); IT

Lower level; Systems are not integrated

No specific KPIs systems' standardisation
LC3 -6 interviews

2015

Become a data-driven company; technologyfocused

Improve machine conditions and data analysis; controlled and stable process; workers' safety; decision-making processes Improve quality, speed, deliverability, innovation and sustainability; strategy under development; no business cases; manufacturing centric

Program manager and global team

Use-cases; meetings; benchmarking

Culture; governance system; digital knowledge and skills; communication; lack of resources (people and investments); top management support; identification of needs; countries with different infrastructures Use-case (sensors)

Data from the use-case has been used for product development; lower level No specific KPIs

technological issues raised by the use-cases: "We have many times been only in the technical side because it's fun and straightforward" (LC2). The companies agreed that digitalisation is not about technology, but it is about the strategy; however, developing a clear strategy is still a goal for all three companies. Even though the discussion was conducted regularly, the companies are still struggling with it. Bosman et al. (2020) recommend that the manufacturers need to start discussing the problem before looking at a potential digital solution. Analysis of strategy and costs needs to be conducted regularly, aligning "pain points" both on the shop floor and business governance structures. 
The companies use different learning sources in strategy development: business cases, benchmarking, workshops, consultancy companies and specialists mapping competences. Company LC2 highlighted the importance of internal development, as they have started a digitalisation program with a big pilot supported by a very well-known consultancy company and the leader affirmed that this was important to increase awareness of the team and top management. However, at some point, they decided to drive the process internally: "Perhaps we can have some input of ideas and competence from external parties, but the implementation still depends on our internal resources, so we need to learn how to navigate by ourselves" (LC2).

LC3 started to discuss digitalisation in 2015, but the findings indicate that organisational barriers were holding back the process, e.g. partial support from the top management and other functions and lack of competence. Two years ago, they decided to tackle these challenges, creating a dedicated team to improve knowledge and promote better communication internally and with other plants. The other two companies started the discussion later, also two years ago, but they had already begun the process of forming a dedicated team.

The use-cases are, in general, focused on speed and flexibility to meet customer needs and on saving resources to improve cost-efficiency. The performance management systems are far from digital, and any new KPI was developed towards digitalisation. LC2 and LC3 are piloting some cases, focussing on improving data analysis capabilities: "To know the purpose of logging the data into the system and to know the benefits of these data as output and build action on that" (LC2); "It's worthless for the operator to see the OEE (Overall Equipment Effectiveness) if we cannot assist in how to improve it" (LC3).

Companies primary interest in a digital readiness assessment varies: "to know our current level and where we are" (SC1); "to prepare the organisation for the digital shift and to identify what the areas are that we need to make sure we cover and support" (LC2); "we need to know what new competencies are required, what type of organisation we need to be, and where we need the technology" (LC3). This last statement shows a good understanding of not starting at the "right" starting point.

Before the interviews, just one of the companies (LC2) had performed a digital readiness assessment, conducted by a consultancy company. The company stated that the evaluation was proper to promote awareness of the top management; however, the assessment was focused on the technical side to identify use-cases without evaluating the organisational and technical infrastructure. The company stated that they were willing to have a simple tool to promote initial and continuous assessment in different units and projects around the digital transformation journey.

Considering the success factors for digital transformation presented by De Sousa Jabbour et al. (2018), the analysis confirmed the gaps previously listed. Among the three cases, it was not possible to identify evidence regarding: strategic alignment between technology and organisational goals; empowerment to support the level of autonomy and responsibility demanded by the decentralised decision-systems; corporate culture (technology adoption and reducing resistance to change); and communication (strategies, clear objectives, collaborative workplace). The only successful factors with evidence among all the cases are management with a transformational style, teamwork and project management.

However, it is essential to emphasise that only the larger companies have established a dedicated team for guiding the digital transformation program. The team is empowered by the top management to plan and implement the digital transformation, identifying gaps in resources, competences and capabilities, taking decisions on investments and define the purpose, vision, goals and strategies to ensure the long-term direction of the digital transformation.

Only one company cited issues related to national culture and regional differences. LC3 reported that when implementing one of its use-cases, they found resistance among the local users of the new digital technology, based on the fear of how the data collected will be used 
JMTM 32,9

178

(performance and errors) and about the fear of losing jobs after the technology adoption. During the local implementation phase, facilitators had to put extra efforts to implement the solution (1 year in total) fully; however, when the same team was escalating the solution to other units abroad, this time was reduced to few weeks instead. The team considers the main reasons for this difference the more robust culture of adaption present in certain countries and openness for "abroad" solutions.

The analysis has adherence with the context provided by previous studies, showing that starting with the proper steps can enable companies to move forward and become fully ready for the digital transformation. Strategic reasons for increasing digitalisation and conducting a digital transformation in manufacturing companies are still narrow.

The transformation process must be conducted by a cross-functional team, supported and empowered by the top management. If necessary, a digital expert can help the leading team in their initial meetings. However, the company needs to walk their path, critically analysing the results from unsuccessful initiatives, celebrating the successful ones creating conditions for scalability, and identifying the resources and competencies necessary to reach the desirable level of maturity. Several rounds of discussion around the questionnaire can be required to ensure the digital transformation's strategic alignment, and the framework can be used as a checklist for each new project.

Therefore, we can infer that these companies' challenges mainly happened in the initial phase of the digital transformation, by the time the companies have started the discussion around the topic and implemented first use-cases using new digital technologies; however, they are still not engaged in the maturing process for digital transformation.

\subsection{Testing organisational readiness conditions}

This section details how the questionnaire based on the readiness conditions was tested and the results of the workshop promoted with a dedicated team, responsible for implementing a digital transformation program at LC3. The team travelled to Sweden to discuss the organisational readiness conditions. In total, it was necessary for more than four hours to discuss all the questions. The team's main challenge during the application of the questionnaire was to realise that, even among them that are leading the global program, not all points discussed were completely clarified or even defined. It was possible to verify the lack of alignment about the needs, opportunity and risks of digitalisation and its strategic benefits among the different business units.

The questions helped the team to take some decisions about the management of local teams, e.g. risk assessments need considering global and local issues and needs, to be performed by the local team; the same is applied for stakeholder's analysis; strength, weakness, opportunities and threats analysis should be institutionalised as a starting point in all projects and results shared with other teams. Future-states scenarios need to be designed on a corporative level and a business units' level, as the business units present differences related to maturity and strategic purposes. The local teams should be responsible for identifying competencies' gaps, and the global team should be the one responsible for placing it on the corporate level and developing plans for improving them.

Business cases will be necessary to secure future investments and engagement of the top management (board level). Results and lessons learnt with use-cases need to be structured and appropriately analysed, and the global team needs to implement a sharing platform where the local groups can share their experiences, knowledge and even resources in the future. Understanding the differences and challenges between the teams can bring an overall level of improvement regarding understanding and engagement in the changing processes.

The global vision of digital transformation needs to be translated into the terms and context of the local teams and the same applies to digital and business strategies. The group agrees that a new structure of KPI's is needed to reflect the effects of the digital transformations. 
The meeting was recorded for the company's use and further discussion. The discussions among the global team on the second day of the workshop validate the questions and the set of condition, making clear for the team the existing gaps that were recognised as issues for the starting-up phase, caused by the lack of appropriated knowledge for leading the digital transformation. The group decided to incorporate the questions in their digital readiness model, which has been developed internally based on benchmarks of digital readiness models available. The questions were tested for the second time by the company in July of 2020 at one of its Korean units. The digital readiness assessment was conducted for five days, led by the global and the local team. The global team was responsible for the opening meeting to align the vision and purpose with the local areas and functions and to empower the local team, which was the one responsible for conducting the assessment. Daily meetings were planned with the local and global team to provide feedback on the questions and the results. One of the researchers was invited to join some of these meetings, more specifically, related to the conditions of organisational readiness. The questions were considered feasible, relevant and a helpful tool to facilitate discussions among the set of conditions to secure digital organisational readiness.

The company reported that without having these points clear for all parts involved, it is not possible to move towards digital transformation. The company can improve the level of digitalisation in some specific and isolated areas, however, without fully taking advantage of the profound organisational changes enabled by Industry 4.0, as pointed by McLaughlin (2017) and Kane et al. (2018). When the whole company can develop new ways to use the digital technologies, it can build innovation in products and services and innovate business processes in the value chain.

\section{Conclusions}

Companies spend time and resources to improve their understanding of the content and context of digital transformation. The appeal of adopting new digital technologies without an appropriate foundation and purpose can increase organisational barriers, undermine engagement and support from the different functions and stakeholders involved and create a strategic misalignment that can jeopardise companies' competitiveness.

This study had the purpose of answering two research questions: RQ1. What organisational conditions need to be assessed to evaluate the organisational readiness for digital transformation in manufacturing companies? RQ2. How should these organisational conditions be organised to support the starting-up processes of digital transformation?

The results validated the set of organisational conditions (RQ1) described in section 2: identify the needs and strategic benefits of digital transformation; identify opportunities and risks of digital transformation; define digital capabilities, competencies and resources for digital transformation; promote digital leadership and cross-functional/units engagement; determine the vision, goals and strategy for digital transformation; promote and enable clear communication with all stakeholders; measure the progress of digital transformation (KPIs); establish mechanisms for digital knowledge management; Stakeholders' empowerment; and escalate the digital transformation across the valuechain (horizontal integration).

The organisational conditions were translated and organised in a questionnaire that could be used as a dialogue tool to promote alignment and leadership engagement leadership, to help to build-up and evaluate teams responsible for encouraging the changes on a local level and could be adapted to specific assessment frameworks already in use by the companies (RQ2). The conditions represent the fundaments of digital organisational readiness, i.e. the minimum requirements that need to be fulfilled to enable companies to mature in the digital transformation journey. 
JMTM 32,9

180

The drivers, challenges and opportunities identified among European manufacturing companies described by Pessot et al. (2020) are like the ones specified in the sample analysed. Companies are still gaining awareness and knowledge of digital transformation. The authors found that all the conditions identified need to be considered in a systemic way defining a strategic roadmap, like the model proposed by Ghobakhloo (2018).

The research contribution is mainly a deeper understanding of how change processes management can be applied to digitalisation in industry, while its limitations rely on its small sample, a not balanced number of respondents among the cases and tests conducted only in one of the companies. Future research and development need to consider further tests in SME's. Future research streams could also follow strategy development processes and adaptation to personnel capabilities in digital technology use.

This research's relevance relies on the fact that companies are advancing in adopting digital technologies without being ready from an organisational readiness perspective. This gap creates barriers for companies' maturing processes, stopping them from having full access to digital technologies' benefits. Choices and investments in technology should be supported by the company's defined "needs" and aligned with its goals, starting the process with a problem to be solved instead of a new technological solution.

The central message of the paper is that the companies need to start "right". We are not trying to reinvent the wheel here but to show that behind the "glamour" of the adoption of new digital technology, there is a "homework" that needs to be done, and manufacturing companies are struggling on how to identify what needs to be done and how to deal with that.

\section{References}

Appelbaum, S.H., Habashy, S., Malo, J. and Shafiq, H. (2012), "Back to the future: revisiting Kotter's 1996 change model”, Journal of Management Development, Vol. 31 No. 8, pp. 764-782, doi: 10. $1108 / 02621711211253231$.

Bosman, L., Hartman, N. and Sutherland, J. (2020), "How manufacturing firm characteristics can influence decision making for investing in Industry 4.0 technologies", Journal of Manufacturing Technology Management, Vol. 31 No. 5, pp. 1117-1141, doi: 10.1108/JMTM-09-2018-0283.

Colli, M., Madsen, O., Berger, U., Møller, C., Vejrum Warhrens, B. and Blockholt, M. (2018), "Contextualising the outcome of a maturity assessment for Industry 4.0", IFAC-PapersOnline, Vol. 51 No. 11, pp. 1347-1352, doi: 10.1016/j.ifacol.2018.08.343.

Combe, M. (2014), "Change readiness: focusing change management where it counts", PMI White Paper, available at: https://www.pmi.org/learning/library/change-readiness-11126.

De Sousa Jabbour, A.B.L., Jabbour, C.J.C., Foropon, C. and Godinho Filho, M. (2018), "When titans meet - can industry 4.0 revolutionise the environmentally-sustainable manufacturing wave? The role of critical success factors", Technological Forecasting and Social Change, Vol. 132, pp. 18-25.

Galbraith, J. (2005), Designing Organizations: An Executive Briefing on Strategy, Structure, and Process, Jossey-Bass, San Francisco, CA.

Garengo, P., Biazzo, S. and Bititci, U.S. (2005), "Performance measurement systems in SMEs: a review for a research agenda", International Journal of Management Review, Vol. 7 No. 1, pp. 25-47, doi: 10.1111/j.1468-2370.2005.00105.x.

Geissbauer, R., Vedso, J. and Stefan, S. (2016), “Industry 4.0: building the digital enterprise - PWC 2016 global industry survey", available at: https://www.pwc.com/gx/en/industries/industries-4.0/ landing-page/industry-4.0-building-your-digital-enterprise_april2016.pdf?_ga =2.102415108. 46912338.1539346626-1416210707.1534188424 (accessed 30 November 2018).

Ghobakhloo, M. (2018), "The future of manufacturing industry: a strategic roadmap toward Industry 4.0", Journal of Manufacturing Technology Management, Vol. 29 No. 6, pp. 910-936. 
Hermann, M., Bücker, I. and Otto, B. (2019), "Industrie 4.0 process transformation: findings from a case study in automotive logistics", Journal of Manufacturing Technology Management, Vol. 31 No. 5, pp. 935-953, doi: 10.1108/JMTM-08-2018-0274.

Hizam-Hanafiah, M., Soomro, M. and Abdullah, N. (2020), "Industry 4.0 readiness models: a systematic literature review of model dimensions", Information, Vol. 11 No. 7, p. 364, doi: 10.3390/ info11070364.

Issa, A., Hatiboglu, B., Bildstein, A. and Bauernhansl, T. (2018), "Industrie 4.0 roadmap: framework for digital transformation based on the concepts of capability maturity and alignment", Procedia CIRP, Vol. 72, pp. 973-978.

Kane, G.C., Palmer, D., Phillips, A.N., Kiron, D. and Buckley, N. (2018), “Coming of age digitally”, June, MIT Sloan Management Review and Deloitte Insights, available at: https://sloanreview.mit.edu/ projects/coming-of-age-digitally/.

Kotter, J.P. (1996), Leading Change, Harvard Business School Press, Boston, MA.

Kotter, J.P. (2014), Accelerate: Building Strategic Agility for a Faster-Moving World, Harvard Business Review Press, Boston, MA.

Lichtblau, K., Stich, V., Bertenrath, R., Blum, M., Bleider, M., Millack, A., Schmitt, K., Schmitz, E. and Schröter, M. (2015), "IMPULS - industrie 4.0-readiness", in Impuls-Stiftung des VDMA, Aachen$K o ̈ l n$, available at: https://www.industrie40-readiness.de/?lang=en.

Lokuge, S., Sedera, D., Grover, V. and Dongming, X. (2019), "Organisational readiness for digital innovation: development and empirical calibration of a construct", Information and Management, Vol. 56 No. 3, pp. 445-461, doi: 10.1016/j.im.2018.09.001.

Machado, C.G., Hurdve, M., Winroth, M. and Bennet, D. (2018), "Production management and smart manufacturing from a systems perspective", Advances in Manufacturing Technology XXXII, Vol. 8 No. XXXII, pp. 329-334, doi: 10.3233/978-1-61499-902-7-329.

Machado, C.G., Winroth, M., Carlsson, D. and Centerholt, V. (2019a), "Digitalization for sustainable production: exploring the use of digital maturity models", Proceedings of the 6th International EurOMA Sustainable Operations and Supply Chains Forum, Gothenburg, March 18-19th.

Machado, C.G., Winroth, M., Carlsson, D., Almström, P., Centerholt, V. and Hallin, Mallin C. (2019b), "Industry 4.0 readiness in manufacturing companies: challenges and enablers towards increased digitalisation”, Procedia CIRP, Vol. 81, pp. 1113-1118, doi: 10.1016/j.procir.2019.03.262.

Machado, C.G., Almström, P., Öberg, A.E., Kurdve, M. and Almashalah, S.Y. (2020), "Maturity framework enabling organisational digital readiness", in Säfsten, K. and Elgh, F. (Eds), Advances in Transdiciplinary Engineering, SPS2020, Vol. 13, pp. 649-660, doi: 10.3233/ ATDE200204.

Mckinsey (2016), "Industry 4.0 after the initial hype", available at: https://www.mckinsey.com/ /media/mckinsey/business $\% 20$ functions/mckinsey $\% 20$ digital/our $\% 20$ insights/getting $\%$ 20 the $\% 20$ most $\% 20$ out $\% 20$ of $\% 20$ industry $\% 204 \%$ 200/mckinsey_industry_40_2016.ashx (accessed 6 November 2018).

McLaughlin, S.A. (2017), "Dynamic capabilities: taking an emerging technology perspective", International Journal of Manufacturing Technology and Management, Vol. 31, pp. 62-81.

Mintzberg, H. (2003), Creating Effective Organisations (In Portuguese), 2nd ed., Atlas, São Paulo.

Nadler, D.A., Shaw, R.B., Walton, A.E. and Associates (1995), Discontinuous Change: Leading Organisational Transformation, The Jossey-Bass management series, Jossey-Bass, San Francisco, CA, pp. 3-44.

Newman, M. (2017), "Digital Maturity Model (DMM): a new tool to navigate the maze of digital transformation", TM Forum White Paper, May, available at: https://www.tmforum.org/trainingcertification/navigating-digital-transformation/ (accessed 6 November 2018).

Nosalska, K., Piątek, Z.M., Mazurek, G. and Rządca, R. (2019), "Industry 4.0: coherent definition framework with technological and organisational interdependencies", Journal of Manufacturing Technology Management, Vol. 31 No. 5, pp. 837-862, doi: 10.1108/JMTM-08-2018-0238. 
JMTM 32,9

Pessot, E., Zangiacomi, A., Battistella, C., Rocchi, V., Sala, A. and Sacco, M. (2020), "What matters in implementing the factory of the future", Journal of Manufacturing Technology Management, Vol. 32 No. 3, pp. 795-819, doi: 10.1108/JMTM-05-2019-0169.

Peters, T.J. and Waterman, R.H. (1982), In Search of Excellence: Lessons from America's Best-Run Companies, Harper \& Row, New York, NY.

Pirola, F., Cimini, C. and Pinto, R. (2019), "Digital readiness assessment of Italian SMEs: a case-study research”, Journal of Manufacturing Technology Management, Vol. 31 No. 5, pp. 1045-1083, doi: 10.1108/JMTM-09-2018-0305.

Pollack, J. and Pollack, R. (2015), “Using Kotter's Eight Stage Process to manage an organisational change program: presentation and practice", Systemic Practice and Action Research, Vol. 28, pp. 51-66. doi: 10.1007/s11213-014-9317-0.

Roos, R. and Nilsson, V.O. (2020), "Driving organisational readiness for change through strategic workshops", International Journal of Management and Applied Research, Vol. 7 No. 1, pp. 1-28, doi: 10.18646/2056.71.20-001.

Ross, J. (2019), "Digital success requires breaking rules", MIT Sloan Management Review, July, available at: https://sloanreview.mit.edu/article/digital-success-requires-breaking-rules/ (accessed 29 October 2019).

Schuh, G., Anderl, R., Gausemeier, J., ten Hompel, M. and Wahlster, W. (Eds) (2017), Industrie 4.0 Maturity Index, Managing the Digital Transformation of Companies (Acatech STUDY), Herbert Utz Verlag, Munich.

Singapore Economic Development Board (2017), "The Singapore smart industry readiness Index: catalysing the transformation of manufacturing", available at: https://www.edb.gov.sg/en/newsand-resources/news/advanced-manufacturing-release.htm.

Stuart, I., McCutcheon, D., Handfield, R., McLachlin, R. and Samson, D. (2002), "Effective case research in operations management: a process perspective", Journal of Operations Management, Vol. 20 No. 5, pp. 419-33, doi: 10.1016/S0272-6963(02)00022-0.

Unruh, G. and Kiron, D. (2017), "Digital transformation on purpose”, MIT Sloan Management Review, November, available at: https://sloanreview.mit.edu/article/digital-transformation-on-purpose/ (accessed 28 March 2018).

Weiner, B.J. (2009), "A theory of organisational readiness for change”, Implementation Science, Vol. 4 No. 67 , doi: 10.1186/1748-5908-4-67.

Yeow, A., Soh, C. and Hansen, R. (2018), "Aligning with new digital strategy: a dynamic capabilities approach", The Journal of Strategic Information Systems, Vol. 27 No. 1, pp. 43-58.

Yin, R. (2014), Case Study Research: Design and Methods, 5th ed., Sage, Thousand Oaks, CA.

\section{Appendix}

The Appendix file(s) is/are available online for this article.

\section{Corresponding author}

Carla Gonçalves Machado can be contacted at: carla.goncalvesmachado@ju.se

For instructions on how to order reprints of this article, please visit our website:

www.emeraldgrouppublishing.com/licensing/reprints.htm

Or contact us for further details: permissions@emeraldinsight.com 